Valerio Gozzoli

Miriam M. Treggiari

Gian-Reto Kleger

Pascale Roux-Lombard

Marc Fathi

Claude Pichard

Jacques-André Romand

\title{
Randomized trial of the effect of antipyresis by metamizol, propacetamol or external cooling on metabolism, hemodynamics and inflammatory response
}

\begin{abstract}
Objective: We investigated the metabolic, hemodynamic, and inflammatory responses of pharmacological and physical therapies aimed at reducing body temperature in febrile critically ill patients. $D e$ sign and setting: Open-label, randomized trial in a surgical ICU in a tertiary university hospital. Patients: Thirty analgosedated, mechanically ventilated patients with a temperature of $38.5^{\circ} \mathrm{C}$ or higher were randomized to receive either intravenous metamizol, intravenous propacetamol, or external cooling. Measurements and results: Body temperature and metabolic and hemodynamic variables were recorded at baseline and during the following $4 \mathrm{~h}$. Cytokine concentrations were assessed before and 4 and $12 \mathrm{~h}$ after the initiation of antipyresis. Body temperature decreased significantly in all treatment groups. For a $1^{\circ} \mathrm{C}$ temperature decrease, the energy expenditure index increased by $5 \%$ with external cooling and decreased by $7 \%$ and $8 \%$ in the metamizol and propacetamol groups, respectively.
\end{abstract}

Metamizol induced a significant decrease in mean arterial pressure and urine output compared to baseline and to the other two groups. Creactive protein increased over time, but compared to the other groups it was significantly lower in patients receiving metamizol after $4 \mathrm{~h}$. Cytokine concentrations were not different among the three groups or over time, although interleukin 6 tended to decrease over time in the metamizol group. Conclusions: Metamizol, propacetamol, and external cooling equally reduced temperature. Considering the undesirable hemodynamic effects, metamizol should not be considered the first antipyretic choice in unstable patients. Propacetamol or external cooling should be preferred, although the latter should be avoided in patients unlikely to tolerate the increased metabolic demand induced by external cooling.

Keywords Adult - Cytokines · Fever - Human - Intensive care unit . Temperature

\section{Introduction}

Fever is a common sign in critically ill patients, related either to systemic inflammatory response syndrome (SIRS) or infection. Although the controversy on the value of treating fever is not settled, when body temperature rises above $38.5^{\circ} \mathrm{C}$, an antipyretic therapy is usually initiated. The treatment options consist of administering drugs such as paracetamol or metamizol and/or applying of external cooling. Arguments advanced in support of reducing fever are the reduction in patient's metabolic demand and the resulting myocardial or cerebral oxygen consumption, and improvement in patient comfort. The deleterious hemodynamic and metabolic consequences of fever are particularly undesirable if a preexisting cardiac disease is present or during sepsis 
where the myocardial function is depressed [1] or in the acute phase of cerebral damage. Furthermore, since these treatments reduce fever through different pathways $[2,3$, 4], their effect on the concentration of plasma inflammatory markers is expected to be different, and this has not been extensively investigated.

In a previous crossover study we demonstrated that antipyresis by physical means is more effective in reducing body temperature than metamizol or propaceta$\mathrm{mol}$, and that a significant decrease in energy expenditure (EE) accompanies the defervescence, probably because sedation blunted the shivering mechanism [5]. However, the lack of randomization, possibly incomplete drug wash-out due to the crossover design, and an antipyretic dose not adjusted for body weight limited the interpretation of the study. Therefore a randomized, prospective, open-label study was designed to investigate the respective effects of centrally acting drugs (propacetamol and metamizol) or external cooling in febrile critically ill patients, on metabolism, hemodynamics, and systemic inflammatory response.

\section{Materials and methods}

Patients and methods

The ethics committee at our institution approved the study. The patient or the next of kin gave informed consent. Inclusion criteria included: age older than 18 years, a Simplified Acute Physiology Score II (SAPS II) greater than 30, and a rectal or core (pulmonary artery) temperature greater than $38.5^{\circ} \mathrm{C}$ for at least $1 \mathrm{~h}$, accompanied by at least two SIRS criteria [6]. Additionally, the lungs had to be mechanically ventilated and the patients hemodynamically stable for at least $6 \mathrm{~h}$ prior to randomization. Exclusion criteria included: renal insufficiency (defined as a creatinine clearance of $<50 \mathrm{ml} / \mathrm{min}$ ), liver dysfunction (defined as the presence of hepatic cirrhosis, and/or a concentration of serum transaminases and bilirubin of greater than twice the upper limit of the normal range), leukopenia, known allergy to metamizol and/or paracetamol, inspired oxygen fraction $\left(\mathrm{FIO}_{2}\right)$ greater than 0.6, pneumothorax, bronchopleural fistula, acute neurological disease, and immunodeficiency or immunosuppressive regimens. Patients were also excluded if propacetamol, paracetamol, or metamizol had been administered between 6 and $16 \mathrm{~h}$ prior to randomization. Thirty patients admitted met the inclusion criteria; all tolerated the protocol well and were included in the analyses. Demographic data and admission diagnoses are shown in Tables 1 and 2 .

Computer generated three-unit block randomization was used for treatment allocation. Patients were randomized to receive an intravenous bolus of metamizol $(16 \mathrm{mg} / \mathrm{kg}$ body weight, maximum of $2 \mathrm{~g}$ ) or propacetamol ( $30 \mathrm{mg} / \mathrm{kg}$ body weight, maximum of $2 \mathrm{~g}$ ) or external cooling by a cooling blanket (Bair hugger, Augustine Medical, Eden Prairie, Minn., USA) and by cloths plunged into iced water and by ice packs applied on most of the body surface. The three treatment groups were similar in baseline characteristics. The level of sedation was similar across groups during the study period; the median (interquartile range) Ramsay score was 5.5 (4.25-6) with metamizol, 5 (4.25-5.75) with propacetamol, and 5 (4-6) with external cooling.

Prior to the beginning of the study analgesia and sedation were adjusted by a continuous infusion of morphine $(\geq 1 \mathrm{mg} / \mathrm{h})$ and midazolam ( $\geq 1 \mathrm{mg} / \mathrm{h}$ ) to obtain a Ramsay sedation score of 4 or higher [7]. Ventilatory settings, adjusted to obtain arterial blood-gas tensions in a normal range, were remained constant during the study. Patients were kept supine during the study and nursing intervention was minimized as much as possible. EE was measured
Table 1 Demographic characteristics of randomized patients, by assigned treatment (SAPS II Simplified Acute Physiology Score II)

Table 2 Distribution of intensive care unit admission diagnoses of randomized patients, by assigned treatment

\begin{tabular}{lccc}
\hline & Metamizol $(n=10)$ & Propacetamol $(n=10)$ & External cooling $(n=10)$ \\
\hline Age $($ years $)$ & $54 \pm 25$ & $55 \pm 14$ & $53 \pm 15$ \\
Sex: M/F & $9 / 1$ & $9 / 1$ & $7 / 3$ \\
SAPS II & $53 \pm 15$ & $51 \pm 17$ & $46 \pm 12$ \\
Ramsay score & $5.1 \pm 1.1$ & $4.8 \pm 1.2$ & $4.8 \pm 1.2$ \\
Midazolam rate $(\mathrm{mg} / \mathrm{h})^{\mathrm{a}}$ & $0.7 \pm 0.5$ & $1.4 \pm 1.3$ & $2.8 \pm 3.0$ \\
Midazolam/24 h & $17.5 \pm 11.4$ & $24.6 \pm 37.8$ & $50.3 \pm 65.3$ \\
Morphine rate $(\mathrm{mg} / \mathrm{h})^{\mathrm{a}}$ & $1.0 \pm 0.7$ & $1.3 \pm 1.4$ & $2.5 \pm 2.9$ \\
Morphine/24 h & $21.9 \pm 17.5$ & $27.4 \pm 36.6$ & $48.9 \pm 81.3$ \\
Nutrition: yes/no & $3 / 7$ & $4 / 6$ & $3 / 7$ \\
kcal/24 h & $763 \pm 456$ & $1268 \pm 970$ & $1497 \pm 669$ \\
Antibiotic use: yes/no & $6 / 4$ & $6 / 4$ & $5 / 5$ \\
ICU mortality $(\%)$ & 50 & 40 & 30 \\
\hline
\end{tabular}

${ }^{a}$ During the study period

${ }^{\mathrm{b}}$ Among patients receiving nutrition

\begin{tabular}{llll}
\hline & $\begin{array}{l}\text { Metamizol } \\
(n=10)\end{array}$ & $\begin{array}{l}\text { Propacetamol } \\
(n=10)\end{array}$ & $\begin{array}{l}\text { External cooling } \\
(n=10)\end{array}$ \\
\hline Acute respiratory distress syndrome & 1 & 0 & 1 \\
Ischemic heart disease & 0 & 2 & 1 \\
Multiple trauma & 2 & 2 & 2 \\
Pancreatitis & 1 & 0 & 1 \\
Pneumonia & 3 & 2 & 1 \\
Sepsis or septic shock & 3 & 4 & 3 \\
Upper gastrointestinal bleeding & 0 & 0 & 1 \\
\hline
\end{tabular}


Table 3 Sensitivity, normal range in human serum, intraand inter-assay coefficient of variation for cytokine measurements

\begin{tabular}{lcllc}
\hline Cytokine & Sensitivity & $\begin{array}{l}\text { Normal range } \\
\text { in human serum }\end{array}$ & \multicolumn{2}{l}{ Coefficient of variation $(\%)$} \\
\cline { 4 - 5 } & & & Intra-assay & Inter-assay \\
\hline IL-6 & $0.7 \mathrm{pg} / \mathrm{ml}$ & $<15 \mathrm{pg} / \mathrm{ml}$ & $<5$ & 4 \\
IL-8 & $10 \mathrm{pg} / \mathrm{ml}$ & $<32 \mathrm{pg} / \mathrm{ml}$ & $<7$ & 10 \\
IL-1Ra & $14 \mathrm{pg} / \mathrm{ml}$ & $106-1552 \mathrm{pg} / \mathrm{ml}$ & $<7$ & 7 \\
TNF $\alpha$ & $4.4 \mathrm{pg} / \mathrm{ml}$ & $<15.6 \mathrm{pg} / \mathrm{ml}$ & $<6$ & 8 \\
TNF-sR75 & $10 \mathrm{pg} / \mathrm{ml}$ & $1.0-3.2 \mathrm{ng} / \mathrm{ml}$ & $<3$ & 6 \\
\hline
\end{tabular}

by indirect calorimetry at baseline to ensure that no patient had a caloric intake higher than required and was standardized by body surface area (energy expenditure index, EEI).

\section{Study protocol}

After randomization hemodynamic and calorimetric variables were recorded. Prior to the initiation of either metamizol, propacetamol, or external cooling a steady state was established, defined as less than $10 \%$ change in both hemodynamic and calorimetric data for at least $30 \mathrm{~min}$. All variables were then measured hourly over a 4-h period $\left[t_{0}\right.$ (prerandomization baseline), $t_{1}, t_{2}, t_{3}, t_{4}$ ). In the external cooling group wet cloths were changed every $30 \mathrm{~min}$ to optimize the cooling treatment. Based on the pharmacokinetic properties of both antipyretic drugs administered, the primary study end-point was defined as the defervescence induced $4 \mathrm{~h}$ after the initiation of the intervention.

Core temperature was measured by a thermistor-tipped pulmonary artery catheter and/or rectal temperature by digital electronic thermometer. Skin temperature was measured on the upper thoracic body surface area by a thermistor-tipped thermometer (Eléctronique, G. Métraux, Crissier, Switzerland). Indirect calorimetry was performed using a Deltatrac II MBM-100 apparatus (Datex Instrumentarium, Helsinki, Finland). Before the patient's connection the Deltatrac II was calibrated for room air, atmospheric pressure, and a standard gas blend containing $95 \%$ oxygen and $5 \%$ carbon dioxide according to the manufacturer's instructions. $\mathrm{CO}_{2}$ production $\left(\mathrm{VCO}_{2}\right)$ is calculated as the product of the $\mathrm{CO}_{2}$ fraction in the diluted expiratory flow and a constant flow of $45 \mathrm{l} / \mathrm{min}$. Oxygen consumption $\left(\mathrm{VO}_{2}\right)$ is calculated as $\dot{\mathrm{VCO}}_{2}$ divided by the respiratory quotient (RQ), where: $\mathrm{RQ}=1-\mathrm{F}_{\mathrm{i}} \mathrm{O}_{2} /\left[\left(\mathrm{F}_{\mathrm{i}} \mathrm{O}_{2}-\mathrm{F}_{\mathrm{E}}{ }^{\prime} \mathrm{O}_{2}\right) /\right.$ $\left.\mathrm{F}_{\mathrm{E}}^{\prime} \mathrm{CO}_{2}\right]-\mathrm{F}_{\mathrm{i}} \mathrm{O}_{2}$.

\section{Data measurements}

Data collected consisted of rectal or core and skin temperatures, heart rate, mean arterial pressure, respiratory rate, expired minute ventilation, arterial $\mathrm{pH}, \mathrm{PaCO}_{2}, \mathrm{PaO}_{2}, \mathrm{HCO}_{3}{ }^{-}$, lactate, $\overline{\mathrm{V}} \mathrm{O}_{2}, \overline{\mathrm{V}} \mathrm{CO}_{2}$, EEI, RQ, and urine output. When a pulmonary artery catheter was in place $(n=25)$, mean pulmonary artery pressure, pulmonary artery wedge pressure, cardiac output, and central venous pressure were also recorded. Arterial blood gas analyses were performed by Stat profile (Nova Biomedical, Boston, Mass., USA). Urine samples were collected hourly and stored at $8^{\circ} \mathrm{C}$ for vanilmandelic acid concentration. Urine samples were processed after the addition of an internal standard by absorption on an anion-exchange column to retain organic acids. Vanilmandelic acid and the internal standard were then eluted and determined by high-performance liquid chromatography with electrochemical detection. Separation was achieved on a reversed-phase column and the detection by electrochemistry in amperometric mode. Quantitation used an internal standard method. Analytical reproducibility for vanilmandelic acid was 7\%. Arterial blood samples for analysis of C-reactive protein (CRP), interleukin (IL) 1Ra, IL-6, IL-8, tumor necrosis factor (TNF) $\alpha$, and TNF-sR75 were taken at baseline and $4 \mathrm{~h}$ and
$12 \mathrm{~h}$ after initiation of treatment. CRP was measured using a nephelometric assay (Immage Beckman). The sensitivity of the assay is $0.4 \mathrm{mg} / \mathrm{l}$. The normal range in human serum is less than $4 \mathrm{mg} / \mathrm{l}$. The sensitivity, normal range in human serum, and intraand interassay coefficients of variation for cytokines are shown in Table 3. IL-6, IL-8, IL-1Ra, TNF $\alpha$, and TNF-sR75 were measured using commercially available quantitative sandwich enzyme immunoassays (Quantikine human, R\&D, UK). Serum samples were assayed at one-fourth dilution. For all the immunoassays the coefficient of variation is less than $7 \%$ for intra-assay and $10 \%$ for interassay.

\section{Statistical analysis}

The study was designed to detect a defervescence from baseline of $1^{\circ} \mathrm{C}$ with a standard deviation of $0.6^{\circ} \mathrm{C}$ based on data from our previous study. Accordingly, the sample size was ten patients per treatment group with a probability of a type I error of 0.05 (twotailed) and a $\beta$ power of 0.95 . Initial exploratory data analysis was conducted to determine the distribution of the baseline characteristics, balance of the randomization process, completeness of data collection, and longitudinal pattern of the observations. At each observation time a cross-sectional analysis of the treatment effect on temperature, metabolism, hemodynamics, and cytokines was performed using analysis of covariance, adjusting for baseline values to increase precision. Cytokine values were log transformed for model building. Generalized estimating equations [8] were used to evaluate the longitudinal effect of treatment on defervescence, metabolism, hemodynamics, and cytokines. All models included treatment as the main predictor and adjusted for baseline values. The level of significance was set at 5\%. Statistical analyses were run using the statistical package STATA (Stata version, 7.0, Tex., USA). Results are reported as means (95\% confidence intervals).

\section{Results}

\section{General characteristics}

Body temperature and metabolism changes

In all treatment groups temperature began to fall significantly $2 \mathrm{~h}$ after the beginning of treatment (Fig. 1a), and after $4 \mathrm{~h}$ the average defervescence was similar between the three groups: $0.9^{\circ} \mathrm{C}, 0.5^{\circ} \mathrm{C}$, and $0.6^{\circ} \mathrm{C}(95 \%$ confidence intervals: 0.5 to $1.2,0.2$ to $0.8,0.4$ to $0.8^{\circ} \mathrm{C}$ ) for metamizol, propacetamol, and external cooling, respectively. In addition, external cooling significantly reduced skin temperature from $35.1 \pm 0.9^{\circ} \mathrm{C}$ to $33.8 \pm 1.4^{\circ} \mathrm{C}$ $(p=0.004) 4 \mathrm{~h}$ after the start of the treatment. There were no differences in temperature between the three groups at 
Fig. 1 Time course of mean body temperature (a), energy expenditure index (b), mean arterial pressure (c) and urinary vanilmandelic acid concentration (d) in patients randomized to receive metamizol, propacetamol, and external cooling. Bars Standard errors. Crosssectional comparison between treatment groups: ${ }^{\dagger} p<0.05$, $\$ p<0.01$, metamizol vs. external cooling, $* p<0.05$ propacetamol vs. external cooling

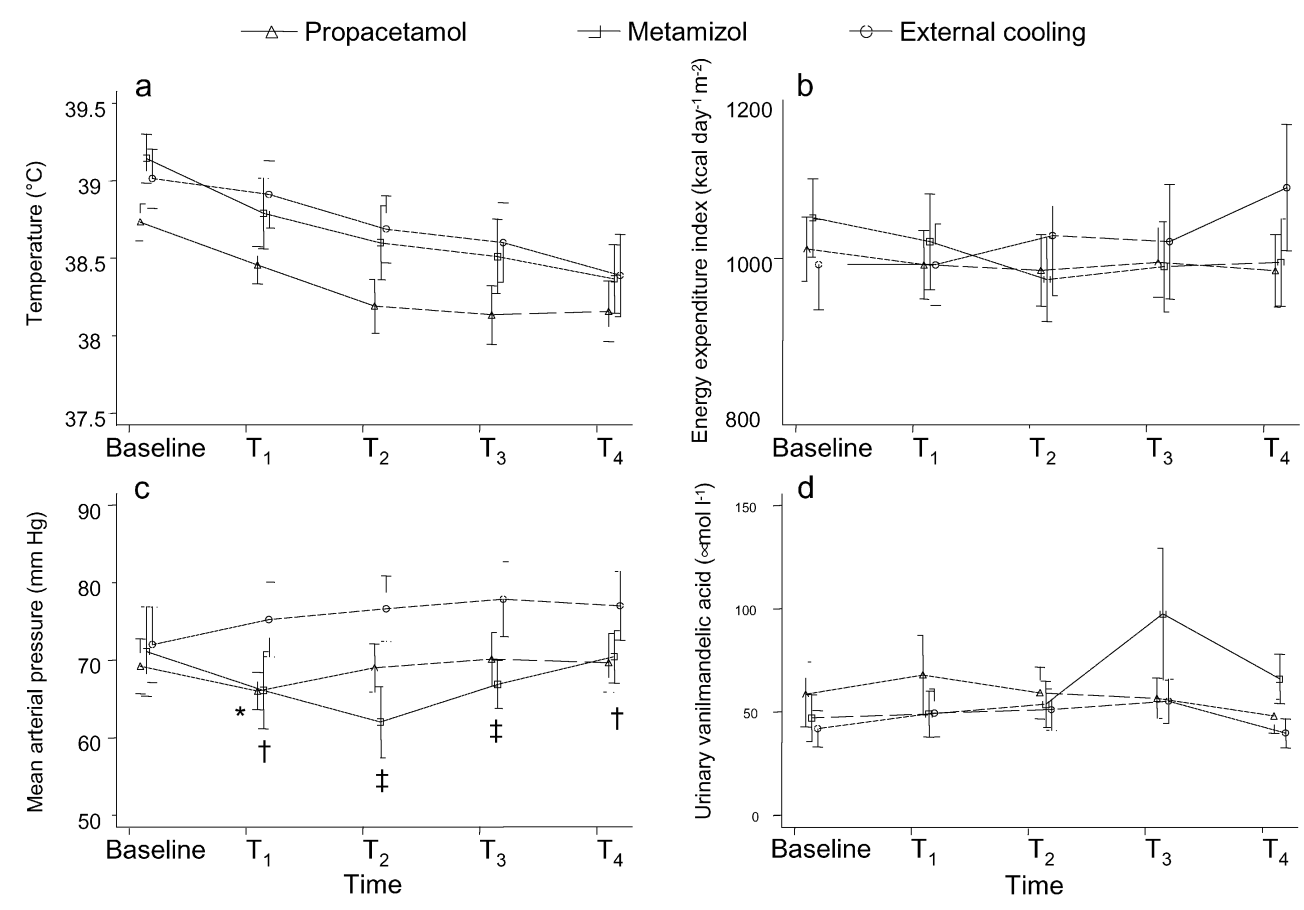

Table 4 Metabolic and hemodynamic variables at baseline and $4 \mathrm{~h}$ after the initiation of antipyresis $\left(t_{4}\right)$, by assigned treatment

\begin{tabular}{|c|c|c|c|c|c|c|}
\hline & \multicolumn{2}{|c|}{ Metamizol $(n=10)$} & \multicolumn{2}{|c|}{ Propacetamol $(n=10)$} & \multicolumn{2}{|c|}{ External cooling $(n=10)$} \\
\hline & Baseline & $t_{4}$ & Baseline & $t_{4}$ & Baseline & $t_{4}$ \\
\hline Core temperature $\left({ }^{\circ} \mathrm{C}\right)$ & $39.1 \pm 5$ & $38.2 \pm * *$ & $38.7 \pm 3$ & $38.2 \pm 6^{*}$ & $39.0 \pm 5$ & $38.4 \pm 7 *$ \\
\hline $\mathrm{CO}_{2}$ production $(\mathrm{ml} / \mathrm{min})$ & $250 \pm 41$ & $232 \pm 44 * *$ & $228 \pm 41$ & $219 \pm 43$ & $239 \pm 61$ & $252 \pm 97$ \\
\hline $\mathrm{O}_{2}$ consumption $(\mathrm{ml} / \mathrm{min})$ & $304 \pm 57$ & $290 \pm 60$ & $263 \pm 38$ & $259 \pm 40$ & $283 \pm 77$ & $315 \pm 96$ \\
\hline Energy expenditure index $\left(\mathrm{kcal} / \mathrm{m}^{2}\right.$ daily) & $1052 \pm 151$ & $994 \pm 169$ & $1012 \pm 124$ & $984 \pm 140$ & $992 \pm 166$ & $1091 \pm 231$ \\
\hline Heart rate (beats/min) & $104 \pm 28$ & $100 \pm 28$ & $112 \pm 17$ & $110 \pm 25$ & $118 \pm 32$ & $112 \pm 32$ \\
\hline Stroke volume $(\mathrm{ml} ; n=8)$ & $74 \pm 39$ & $75 \pm 35$ & $57 \pm 17$ & $62 \pm 20$ & $70 \pm 35$ & $69 \pm 29$ \\
\hline Mean arterial pressure $(\mathrm{mmHg})$ & $71 \pm 16$ & $70 \pm 10$ & $70 \pm 11$ & $72 \pm 13$ & $73 \pm 12$ & $78 \pm 12 *$ \\
\hline Pulmonary artery wedge pressure $(\mathrm{mmHg} ; n=8)$ & $17 \pm 6$ & $17 \pm 8$ & $13 \pm 3$ & $14 \pm 4$ & $16 \pm 8$ & $15 \pm 5$ \\
\hline Urine output $(\mathrm{ml} / \mathrm{h})$ & $55 \pm 42$ & $25 \pm 19 *$ & $44 \pm 52$ & $47 \pm 45$ & $76 \pm 56$ & $69 \pm 52$ \\
\hline
\end{tabular}

$* p<0.05, * * p<0.01$, baseline vs. $t_{4}$

any time point during the entire study period either in the cross-sectional or the longitudinal analyses.

Metabolic variables are shown in Table 4 and Fig. $1 b$. Adjusting for baseline, there was a significant difference at $4 \mathrm{~h}$ in mean EEI between the propacetamol and metamizol groups vs. the external cooling group. The mean daily EEI was $125.5 \mathrm{kcal} / \mathrm{m}^{2}(-243.1$ to -7.9 , $p=0.037)$ lower with propacetamol and $151.3 \mathrm{kcal} / \mathrm{m}^{2}$ $(-270.5$ to $-32.0, p=0.015)$ lower with metamizol than in the external cooling group. Also, $\mathrm{VO}_{2}$ was different between the groups after $4 \mathrm{~h}$, being significantly lower in the propacetamol group $(-44.53 \mathrm{ml} / \mathrm{min},-82.17$ to -6.90 , $p=0.022)$ and metamizol group $(-45.11 \mathrm{ml} / \mathrm{min},-83.47$ to $-6.75, p=0.023$ ) than the external cooling group. Similarly, over the entire study period the effect of external cooling on $\dot{\mathrm{VO}}_{2}$ differed significantly from that in the other two treatments: compared with external cooling there was a mean $\mathrm{VO}_{2}$ difference of $-22.4 \mathrm{ml} / \mathrm{min}(-43.5$ to -1.26 ) with propacetamol and one of $-25.7 \mathrm{ml} / \mathrm{min}$ $(-49.2$ to -2.18$)$ with metamizol for every hour elapsed. The difference in daily EEI between external cooling and propacetamol was $-65.7 \mathrm{kcal} / \mathrm{m}^{2}(-149.2$ to 17.8$)$ and that between external cooling and metamizol was $-102.2 \mathrm{kcal} /$ $\mathrm{m}^{2}(-173.4$ to -30.9$)$. During the study period there was a nonsignificant increase in EEI and $\mathrm{VO}_{2}$ by $5 \%$ (-3\% to $13 \%, p=0.188)$ and $13 \%(-1 \%$ to $28 \%, p=0.06)$ respectively, per $1{ }^{\circ} \mathrm{C}$ of temperature reduction in the external cooling group, while EEI decreased by $7 \%$ (4\% to $10 \%$, $p<0.01)$ per $1{ }^{\circ} \mathrm{C}$ of temperature reduction in the metamizol and by $8 \%(3 \%$ to $12 \%, p<0.01)$ per $1^{\circ} \mathrm{C}$ of temperature reduction in the propacetamol group. 
Table 5 Biological assay variables at baseline and $12 \mathrm{~h}$ after the initiation of antipyresis $\left(t_{12}\right)$, by assigned treatment

\begin{tabular}{|c|c|c|c|c|c|c|}
\hline & \multicolumn{2}{|c|}{ Metamizol $(n=10)$} & \multicolumn{2}{|c|}{ Propacetamol $(n=10)$} & \multicolumn{2}{|c|}{ External cooling $(n=10)$} \\
\hline & Baseline & $t_{12}$ & Baseline & $t_{12}$ & Baseline & $t_{12}$ \\
\hline CRP (mg/l) & $267 \pm 74$ & $285 \pm 88$ & $207 \pm 91$ & $248 \pm 124^{*}$ & $233 \pm 70$ & $271 \pm 95^{*}$ \\
\hline IL-1Ra (ng/ml) & $46.5 \pm 61.5$ & $61.5 \pm 14.2$ & $35.4 \pm 59.0$ & $15.6 \pm 19.0$ & $22.3 \pm 24.3$ & $13.8 \pm 17.3^{*}$ \\
\hline IL-6 (ng/ml) & $4.2 \pm 9.7$ & $1.0 \pm 1.6^{*}$ & $10.5 \pm 29.7$ & $4.3 \pm 11.9$ & $2.4 \pm 3.7$ & $2.4 \pm 4.1$ \\
\hline IL-8 (ng/ml) & $0.19 \pm 35$ & $0.10 \pm 0.01$ & $0.61 \pm 1.48$ & $0.26 \pm 0.50$ & $0.40 \pm 0.69$ & $0.13 \pm 0.20$ \\
\hline TNF $\alpha(\mathrm{pg} / \mathrm{ml})$ & $15.2 \pm 0.7$ & $15 \pm 0$ & $18.0 \pm 7.6$ & $15 \pm 0$ & $17.0 \pm 5.6$ & $15.7 \pm 1.9$ \\
\hline TNF-sR75 (ng/ml) & $6.0 \pm 3.1$ & $6.1 \pm 2.4$ & $5.6 \pm 3.8$ & $5.3 \pm 3.3$ & $5.4 \pm 3.3$ & $4.8 \pm 1.9$ \\
\hline
\end{tabular}

$* p<0.05$, baseline vs. $t_{12}$

The $\mathrm{PaO}_{2} / \mathrm{FIO}_{2}$ ratio did not change significantly, but respiratory rate and expired minute ventilation fell significantly during the study in the metamizol group. No significant changes and differences between the treatment groups were found for $\mathrm{pH}, \mathrm{PaO}_{2}, \mathrm{PaCO}_{2}$, $\mathrm{HCO}_{3}^{-}$, or serum lactate concentration.

\section{Hemodynamic changes}

Systemic and pulmonary hemodynamic variables are shown in Table 4. Mean arterial pressure decreased from $71 \pm 16 \mathrm{mmHg}$ at baseline to $62 \pm 13 \mathrm{mmHg}$ at $t_{2}$ after the administration of metamizol $(p=0.008)$ and then returned to baseline values at $t_{4}$. Mean arterial pressure was significantly lower in the metamizol group than the external cooling group at all the time points after baseline (Fig. 1c). The longitudinal effect of external cooling on blood pressure differed significantly from that of the other two treatments: compared with external cooling there was a mean difference of $-4.8 \mathrm{mmHg}(-7.8$ to -1.8$)$ with propacetamol and $-7.8 \mathrm{mmHg}(-11.45$ to -4.07$)$ with metamizol. Concomitant with the reduction in blood pressure there was a decrease from baseline in urine output at $t_{3}$ and $t_{4}$ (Table $4 ; p=0.012$ ) in the metamizol group. The difference was significant compared with that in the external cooling group at $t_{3}$ and $t_{4}$ (overall mean difference: $-16.8 \mathrm{ml} / \mathrm{h},-33.4$ to -28.0 ). No changes in cardiac output, mean pulmonary artery, mean pulmonary artery wedge, or central venous pressures were observed during the study period.

\section{Biological assay}

Overall CRP increased after $12 \mathrm{~h}$ in all groups by a mean of $28.7 \pm 12.5 \mathrm{mg} / \mathrm{l}(p=0.033)$. Compared with the external cooling group CRP was significantly lower at $t_{4}$ in the propacetamol group $(-39.45 \mathrm{mg} / \mathrm{l},-66.75$ to -12.15 , $p=0.007$ ) after adjusting for baseline values. The group receiving metamizol did not differ from the external cooling group. IL-6, IL-8, and IL-1ra were highly elevated at baseline compared to normal concentrations
(Table 5). Overall the log IL-6 decreased by $0.402 \pm 1.15 \mathrm{pg} / \mathrm{ml}$ after $4 \mathrm{~h}$ compared to baseline $(p=0.017)$. At $t_{4}$ and $t_{12}$ the decrease in log IL-6 was marginally significant in the metamizol group compared to baseline ( $p=0.08$ and $p=0.04$, respectively). However, there were no significant differences among the three groups. No patterns over time or differences across the groups were found for IL- 8 and IL-1Ra. TNF $\alpha$ was only slightly increased in a few patients and remained within the normal range for most patients. TNF-sR75, which prevents the binding of TNF $\alpha$ to its membrane receptor, was also only slightly elevated, without changes upon treatment. Similarly, no significant changes between the treatment groups were observed in urine concentrations of vanilmandelic acid (Fig. 1d). Consistent with this, in all treatment groups SIRS was still present in a comparable number of patients $12 \mathrm{~h}$ after start of antipyresis ( 9 of 10 , 10 of 10 , and 8 of 10 with metamizol, propacetamol, and external cooling, respectively).

\section{Discussion}

The present findings show that pharmacological and physical means are equally effective in reducing temperature. Metamizol and propacetamol, but not external cooling, reduced $\mathrm{EE}$ and oxygen consumption by 5-7\% for every $1{ }^{\circ} \mathrm{C}$ decrease in temperature. After $4 \mathrm{~h}$ EE was significantly higher in the external cooling group than the other two groups. However, metamizol significantly decreased blood pressure and urine output, while mean arterial pressure was unchanged with propacetamol, and increased with external cooling. During defervescence there was an overall increase in CRP, but this increase was blunted after $4 \mathrm{~h}$ in patients receiving metamizol. No patterns over time or important differences across the groups were found for other cytokines.

In agreement with the physiological response to a cold stress, which normally consists in heat conservation and heat production, external cooling increased $\mathrm{EE}$ in the patients studied despite the decrease in body temperature. In contrast with this observation, previous studies reported that external cooling decreases EE, possibly because 
shivering was suppressed by sedation or therapeutic paralysis [5, 9]. However, in our externally cooled patient group EE increased despite clinically adequate sedation and the absence of a visible shivering response, suggesting that the increase in EE by external cooling involves other mechanisms than shivering which are not entirely blunted by sedation. The reason for the decrease in EE with external cooling in the above studies could be treatment crossover and/or the prior administration of antipyretic drugs, causing the hypothalamic thermostat to reset at a normal level. Therefore the body may have reacted with heat loosing mechanisms rather than heat production, thus exhibiting a decrease in EE. We specifically addressed this point when we designed the study. Indeed, no treatment crossover was allowed, and only patients free of prior antipyretic agents were enrolled.

In the present study the lack of a role of shivering in increasing $\mathrm{EE}$ is further supported by the absence of concomitant increased catecholamine secretion. However, shivering cannot definitively be discarded given the lack of neuromuscular blockade in our patients, even though no clinical signs of mild shivering were detected, and electrocardiographic recordings did not suggest background noise in the tracing. Other possible mechanisms of nonshivering thermogenesis through brown adipose tissue would be very unlikely in adults $[10,11]$. In patients treated with metamizol or propacetamol we found a 5-7\% decrease in EE per $1{ }^{\circ} \mathrm{C}$ of defervescence. This observation is consistent with recent data reporting a 6-10\% change in metabolism per $1{ }^{\circ} \mathrm{C}$ change in body temperature $[5,9,12,13]$ and contrasts with an earlier study showing more important changes in metabolism in the order of $13 \%$ per $1{ }^{\circ} \mathrm{C}$ of change in body temperature [14]. The latter study may have suffered from less sophisticated metabolic measurement techniques and referred to normal, conscious individuals. On the other hand, the change in metabolic rate may be not linear over different ranges of temperature.

Few studies have evaluated the cardiovascular response to antipyresis in the critically ill febrile patient. Previous investigations observed that the resolution of fever without antipyretic treatment increased the left ventricular stroke volume index and concluded that the left ventricular performance is enhanced as a result of defervescence [1, 15]. Although effective as antipyretic agent, metamizol induced undesirable hemodynamic effects. Indeed, metamizol infusion reduced mean arterial pressure by about $10 \mathrm{mmHg}$ and required an increase in vasoactive doses in all treated patients. Metamizolinduced hypotension has previously been reported in a retrospective study describing severe hypotensive episodes every 300 patients receiving parenteral administration $[16,17]$. The incidence of hypotension was much higher in the present study and was observed exclusively in patients requiring hemodynamic support. The hypo- tension may be caused by peripheral vasodilatation due to the known smooth-muscle cell relaxing effect of metamizol and/or by a not yet described negative inotropic property of the drug. These hemodynamic effects are probably not innocuous because some degree of repercussion on tissue perfusion was probably present after metamizol infusion. Indeed, the fall in urine output could reflect such decreased renal perfusion. Inhibition of the prostaglandin synthesis, which may lead to the retention of sodium and water and to a decrease in glomerular filtration may have also occurred and account for the fall in urine output.

The inflammatory response was not influenced by the three antipyretic treatments, as seen by the lack of significant changes between the treatment groups in serum cytokine concentrations. However, metamizol seemed to have a short-lived effect (within $4 \mathrm{~h}$ ) in reducing CRP and IL-6. Consistent with this, in all treatment groups SIRS was clinically persisting in almost all patients $12 \mathrm{~h}$ after the start of antipyresis. The endogenous mediators of fever IL-6 and IL-8 are markedly elevated in patients when fever reaches $38.5^{\circ} \mathrm{C}$ and this is in agreement with other studies [18, $19,20]$. Moreover, circulating levels of IL-6 are known to have the highest correlation with changes in body temperature $[19,20]$, and in our patients IL-6 and IL-8 concentrations tended to decrease upon treatment. This effect was noted only in the group receiving metamizol. Therefore the mechanism of this decrease remains unclear because prostaglandin $E_{2}$ is involved in fever induced by IL-6 [21] but not in that induced by IL-8, and the same effect should have been observed with propacetamol via the inhibition of prostaglandin $\mathrm{E}_{2}$. IL-1Ra, as with IL-1, is induced by inflammatory stimuli and prevents the action of IL- 1 if it reaches a molar ratio greater than 500:1. In animal models IL-1Ra limits the duration rather than the magnitude of fever [22]. IL-1 concentrations, which are rarely detectable at the systemic level, were not measured, but we observed high concentrations of circulating IL-1Ra, which were not effective in preventing induction of fever in our patients. It is likely that in these patients IL-1Ra rather reflects the inflammatory response, IL-1Ra being a very sensitive acute-phase protein [23].

Antipyretic therapy is often prescribed in clinical practice when body temperature reaches $38.5^{\circ} \mathrm{C}$ and is considered to have failed if no clinically relevant effect is observed within $2 \mathrm{~h}$ after the administration. However, the present study points out that curtailing the time required for the drug to be effective is presumably inappropriate. Indeed, if correct doses adapted to body weight are applied (16 mg/kg body weight for metamizol, $30 \mathrm{mg} / \mathrm{kg}$ body weight for propacetamol) the peak antipyretic action is expected to be $3-4 \mathrm{~h}$ after administration. Therefore only after this period should other antipyretic treatments be considered, if no effect is noted. 
In conclusion, considering the lack of superiority in decreasing temperature compared to other treatments, the adverse effects on hemodynamics and the association of metamizol with the rare but life-threatening agranulocytosis [24, 25] the use of metamizol as a standard antipyretic treatment should be discouraged, especially in hemodynamically unstable patients. Indeed, the beneficial effects on metabolism are of minor clinical relevance and do not justify its administration. Equally efficient antipyretic treatments such as propacetamol and external cooling should be preferred. However, special consideration should be given to patients who are unlikely to tolerate the increased metabolic demand that may accompany external cooling, despite adequate sedation. Uncertainty remains as to whether fever in itself, as distinct from its cause, is beneficial or harmful, and what circumstances warrant antipyretic therapy.

Acknowledgements We are grateful to Jean-Michel Dayer for his help in designing the study and to Marjan Mohitzadeh and Christine Modoux for their skillful technical assistance.

\section{References}

1. Haupt MT, Rackow EC (1983) Adverse effects of febrile state on cardiac performance. Am Heart J 105:763-768

2. Shimada SG, Otterness IG, Stitt JT (1994) A study of the mechanism of action of the mild analgesic dipyrone. Agents Actions 41:188-192

3. Boutaud O, Aronoff DM, Richardson JH, Marnett LJ, Oates JA (2002) Determinants of the cellular specificity of acetaminophen as an inhibitor of prostaglandin H (2) synthases. Proc Natl Acad Sci U S A 99:7130-7135

4. Coimbra C, Boris-Moller F, Drake M, Wieloch T (1996) Diminished neuronal damage in the rat brain by late treatment with the antipyretic drug dipyrone or cooling following cerebral ischemia. Acta Neuropathol (Berl) 92:447-453

5. Poblete B, Romand JA, Pichard C, Konig P, Suter PM (1997) Metabolic effects of i.v. propacetamol, metamizol or external cooling in critically ill febrile sedated patients. Br J Anaesth 78:123-127

6. Bone RC, Balk RA, Cerra FB, Dellinger RP, Fein AM, Knaus WA, Schein RM, Sibbald WJ (1992) Definitions for sepsis and organ failure and guidelines for the use of innovative therapies in sepsis. The ACCP/SCCM Consensus Conference Committee. American College of Chest Physicians/Society of Critical Care Medicine. Chest 101:1644-1655

7. Ramsay MA, Savege TM, Simpson BR, Goodwin R (1974) Controlled sedation with alphaxalone-alphadolone. BMJ 2:656-659

8. Burton P, Gurrin L, Sly P (1998) Extending the simple linear regression model to account for correlated responses: an introduction to generalized estimating equations and multi-level mixed modelling. Stat Med 17:12611291
9. Manthous CA, Hall JB, Olson D, Singh M, Chatila W, Pohlman A, Kushner R, Schmidt GA, Wood LD (1995) Effect of cooling on oxygen consumption in febrile critically ill patients. Am J Respir Crit Care Med 151:10-14

10. Astrup A, Bulow J, Christensen NJ, Madsen J (1984) Ephedrine-induced thermogenesis in man: no role for interscapular brown adipose tissue. Clin Sci (Colch) 66:179-186

11. Plattner O, Semsroth M, Sessler DI, Papousek A, Klasen C, Wagner O (1997) Lack of nonshivering thermogenesis in infants anesthetized with fentanyl and propofol. Anesthesiology 86:772-777

12. Bruder N, Raynal M, Pellissier D, Courtinat C, Francois G (1998) Influence of body temperature, with or without sedation, on energy expenditure in severe head-injured patients. Crit Care Med 26:568-572

13. Stettler N, Schutz Y, Whitehead R, Jequier E (1992) Effect of malaria and fever on energy metabolism in Gambian children. Pediatr Res 31:102-106

14. DuBois E (1954) Energy metabolism. Annu Rev Physiol 16:125-134

15. Pesenti A, Riboni A, Basilico E, Grossi E (1986) Antipyretic therapy in ICU patients: evaluation of low dose diclofenac sodium. Intensive Care Med $12: 370-373$

16. Zoppi M, Hoigne R, Keller MF, Streit F, Hess T (1983) [Reducing blood pressure with Dipyron (novaminsulfone sodium)]. Schweiz Med Wochenschr 113:1768-1770

17. Hoigne R, Zoppi M, Sollberger J, Hess T, Fritschy D (1986) Fall in systolic blood pressure due to metamizol (dipyrone, noramidopyrine, novaminsulfone). Results from the Comprehensive Hospital Drug Monitoring Berne (CHDMB). Agents Actions Suppl 19:189-195
18. Jansky L, Vybiral S, Pospisilova D, Roth J, Dornand J, Zeisberger E Kaminkova J (1995) Production of systemic and hypothalamic cytokines during the early phase of endotoxin fever. Neuroendocrinology 62:55-61

19. Roth J, Conn CA, Kluger MJ, Zeisberger E (1993) Kinetics of systemic and intrahypothalamic IL-6 and tumor necrosis factor during endotoxin fever in guinea pigs. Am J Physiol 265:R653658

20. LeMay LG, Vander AJ, Kluger MJ (1990) Role of interleukin 6 in fever in rats. Am J Physiol 258:R798-803

21. Zampronio AR, Souza GE, Silva CA Cunha FQ, Ferreira SH (1994) Interleukin-8 induces fever by a prostaglandin-independent mechanism. Am J Physiol 266:R1670-1674

22. Cartmell T, Luheshi GN, Hopkins SJ, Rothwell NJ, Poole S (2001) Role of endogenous interleukin-1 receptor antagonist in regulating fever induced by localised inflammation in the rat. J Physiol (Lond) 531:171-180

23. Gabay C, Smith MF, Eidlen D, Arend WP (1997) Interleukin 1 receptor antagonist (IL-1Ra) is an acute-phase protein. J Clin Invest 99:2930-2940

24. International Agranulocytosis and Aplastic Anemia Study (1986) Risks of agranulocytosis and aplastic anemia. A first report of their relation to drug use with special reference to analgesics. JAMA 256:1749-1757

25. Hargis JB, La Russa VF, Redmond J, Kessler SW, Wright DG (1989) Agranulocytosis associated with "Mexican aspirin" (dipyrone): evidence for an autoimmune mechanism affecting multipotential hematopoietic progenitors. Am J Hematol 31:213-215 